\begin{tabular}{|l|c|} 
Proceeding of the $^{\text {th }}$ ICEE Conference 3-5 April 2018 & NRA \\
Military Technical College \\
Kobry El-Kobbah, \\
Cairo, Egypt
\end{tabular}

NRA-4

\title{
Study of Some Parameters Affecting Efficiency of HpGe Detectors for Accurate Radionuclides Analysis
}

\author{
M.sayed ${ }^{1}$, Mohamed A.E. Abdel-Rahman ${ }^{1}$, Sayed A. El-Mongy ${ }^{2}$
}

\begin{abstract}
In fact, optimized and adjusted parameters of analysis techniques are critical issues and lead strongly to accuracy and high confidence of results. This study is mainly focus on investigation (validation and verification; $\mathrm{V} \& \mathrm{~V}$ ) of some parameters affecting the efficiency and efficacy of HpGe gamma spectrometers; voltage variation, shaping time, type of detectors (n-type or p-type), geometry (size) of detector, source to detector distance and density of the sample matrix. Three different HpGe detectors with their electronics were used to carry out this work. The standard sources; ${ }^{137} \mathrm{Cs},{ }^{60} \mathrm{Co},{ }^{57} \mathrm{Co}$, ${ }^{133} \mathrm{Ba}$ were used. The source-to-detector distance of $25 \mathrm{~cm}$ was optimized to avoid the coincidence summing and dead-time correction. The efficiency curves of the spectrometers have been measured and presented at the above-mentioned parameters. A simulated reference efficiency curve at different parameters using standard point sources was also produced by Angel-3 software. The noises of electronics due to the electromechanical cooling system were also investigated. The optimum parameters were selected for precise analysis of some samples (Black sand and El-Dabaa site) at 3300V and $4000 \mathrm{~V}$ for p-type and n-type detector respectively. It was observed that n-type detector has better efficiency than p-type especially at low energy below $120 \mathrm{KeV}$. It covers energies from $10 \mathrm{keV}$ to $3 \mathrm{MeV}$. The analyses found also that the density has a strong effect on efficiency curve below energy $250 \mathrm{keV}$. The results obtained at different parameters are discussed, interpreted and presented as figures
\end{abstract}

Keywords:

HpGe / efficiency variation / Analysis parameters / Angel-3 software

\footnotetext{
${ }^{\mathrm{T}}$ Nuclear Engineering Department, Military Technical College, Cairo, Egypt

${ }^{2}$ Nuclear and Radiological Regularity Authority (ENRRA), Nasr city, Cairo, Egypt
} 


\section{Military Technical College \\ Kobry El-Kobbah, Cairo, Egypt}

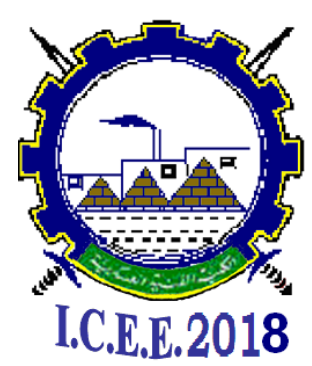

9 $\frac{\text { th }}{\text { International Conference }}$ on

Chemical \& Environmental Engineering

3-5 April 2018

\section{Introduction}

Non-destructive technique gamma spectrometry is an effective and essential tool to analyze different materials and matrixes containing natural and/or anthropogenic radionuclides [1] and all nuclear fuel cycle stages. The dominant and great superiority characteristic of germanium detectors is their excellent energy resolution that allows the separation of many closely space gamma-ray energies which remain unresolved in the $\mathrm{NaI}$ (T1) spectrum [2] .The most important in the analysis using a gamma ray spectrometer is the determination of the number of photons emitted by the source and received by the detector [3]. Energy and Efficiency calibration are important for the qualitative and quantitative analysis of the samples containing radioactive nuclei to accurately determining activity concentrations. Correct and reliable determination of the efficiency curve is of great importance for analysis.

Thera are three main calibration tasks to be achieved; energy calibration (the relationship between channels and energy), peak width calibration (the variation of peak width with energy) and efficiency calibration (the relationship between number of counts and disintegration rate) [4].

The calibration of an analytical system is one of the most important tasks required of all analysts. If the calibration is incorrect then all the result produced will be inaccurate the essential requirement of calibration is to establish relationship between energy, efficiency and resolution. For gamma-ray measurement with Ge detector, the position of photo peak (full energy peak) is relevant for energy measurements [5].

Many factors affect detector efficiency; such as voltage variation, shaping time, type of detectors (n-type or p-type), geometry (size) of detector, source to detector distance, density of the sample matrix, geometry of the sample, stability of the cooling system and electronics connected to the detector, characteristics of the standard calibration sources and the analytical treatment methods of the results. However, in many cases, these conditions cannot be fulfilling the standard radioactive and samples, even if available, are costly and would need to be renewed, especially when the radionuclides have short half-lives [6].

Modeling software Angle-3 offers an alternative method to direct calibration of the spectrometers; the technique is time efficient and can be adapted for any sample delivered to the laboratory for measurement. The method has been adopted by commercial instrument companies, which has the advantage that the calculations are an integral part of the analysis software, simplifying routine operation [7] .

This paper focuses mainly on characterization of high purity Germanium (HpGe) detectors as non-destructive assay tools. Different parameters affecting the spectrometer performance; the FEP (full energy peak efficiency) are studied. The efficiency curve 
Military Technical College

Kobry El-Kobbah, Cairo, Egypt

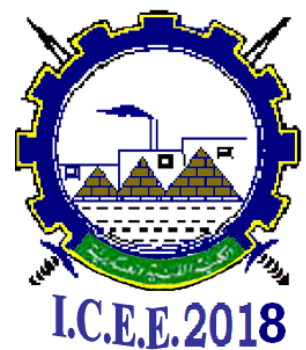

$9^{\text {th }}$ International Conference on

Chemical \& Environmental

Engineering

3-5 April 2018

covering the energy to maximum photon energy of $1332 \mathrm{KeV}$ was carried out. Angle-3 software will be used to make simulation of efficiency calibration curve with different sample density.

\section{Experimental work:}

\subsection{Measurement Arrangement}

In this study, all the curves of (voltage variation, source to detector distance and comparison between detector types) were achieved by using two high-resolution gamma ray spectroscopy technique with a high-purity germanium $(\mathrm{HpGe})$ detector of the same relative efficiency $\sim 50 \%$ efficiency. The two HpGe detectors, with its built-in preamplifier, is operated with a high voltage power supply at approximately 3.3 and $4 \mathrm{kV}$ for p-type and n-type, respectively. The output signal was connected to a spectroscopy amplifier, followed by a multi-channel analyzer (MCA) with 16k channels for both detectors. The shaping time was adjusted to 8 and $6 \mu$ s for p-type and n-type, respectively. The curves of $2 \Pi$ and $4 \Pi$ geometry measurement, density and comparison between point and bulk source were achieved by using p-type $100 \%$ at $4.5 \mathrm{kV}$ with adjusted shaping time $19 \mu \mathrm{s}$. Finally, the spectra of all point and standard sources were analyzed using computer GENIE 2000 software for system A and GAMMA VISION for system $\mathrm{B}$ and $\mathrm{C}$. The Main technical specifications of the three $\mathrm{HpGe}$ detector are given in Table (1) whose the detectors are labeled as A, B and C)

\subsection{Standard Sets of Calibration Sources:}

All the efficiency curves for different systems had been achieved using point sources, which were established with Nist traceable mixed nuclide standard Analytics Serial Number SRS 80899-854 The energy of gamma ray represents ranges from the $81-\mathrm{keV}$ to $1332 \mathrm{KeV}$ their data are listed in Table 2. A solid matrix standard source established with Eckert \& Ziegler, Analytics Serial Number SRS 84875-565, ranges from the $59 \mathrm{keV}$ to $1332 \mathrm{KeV}$ their data are listed in Table 3.

\subsection{Effect of voltage variation parameter:}

The relationship between thickness of the depletion layer and the bias voltage is [2]:

$$
(\mathrm{d} \propto \sqrt{ } \mathrm{V})
$$

The proportionality check of increasing the bias voltage to attain a larger active volume was carried out experimentally by using different point sources at $25 \mathrm{~cm}$ from the 
Military Technical College Kobry El-Kobbah, Cairo, Egypt

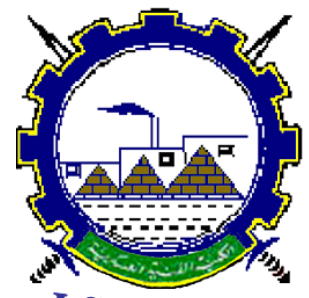

I.C.E.E.2018 $9^{\text {th }}$ International Conference on

Chemical \& Environmental Engineering

3-5 April 2018

detector cap [8].The maximum applied voltage on the crystal $3.3 \mathrm{~V}$ and $4 \mathrm{kV}$ for p-type and n-type, respectively. The depletion voltage of the p-type detector is $2.3 \mathrm{kV}$. The gamma spectra from the point sources were measured for 3600 seconds [9].

\subsection{Source to detector distance parameter:}

The count rate $\mathrm{R}$ vary with the distance according to the inverse square law is thus [4]:

$$
\mathrm{R} \propto 1 / \mathrm{d}^{2}
$$

The distance $\mathrm{d}$ is the sum of the known source-to detector cap distance, D, and the unknown distance from the point-of-action within the detector to the detector cap, $\mathrm{d}_{0}$ :

$$
\mathrm{d}=\mathrm{D}+\mathrm{d}_{0}
$$

The value of $\mathrm{d}_{0}$ is not constant but depends upon the energy of the gamma ray. Variation of efficiency and energy curves for different distances from the detector cap, 5, 10 and 25 $\mathrm{cm}$ of the point sources has been plotted. The point sources were measured for 3600 seconds.

\subsection{Source density parameter:}

The absorption processes are a function of energy and described by the exponential attenuation equation below [10]:

$$
\mathrm{I}=\mathrm{I}_{0} \mathrm{e}^{-\mu \mathrm{x}}
$$

That a gamma-ray of initial intensity $\mathrm{I}_{0}$, after traversing a thickness $\mathrm{x}$ of absorber and the total linear attenuation coefficient $\mu$. Two experimental efficiency curves were established using p-type detector $100 \%$ and two similar standard sources containing same isotopes and geometry but with different densities $(1.15$ and $1.5 \mathrm{~g} / \mathrm{cm} 3)$. Simulation of different efficiency curves with different densities was carried out by using Angle-3 software [7].

\subsection{Efficiencies of different detector type:}

The efficiency for various energies with two different types of spectrometers; (p-type) and (n-type) with the same relative efficiency $50 \%$ was carried out by using point sources of energy ranging from $81 \mathrm{keV}$ to about $1332 \mathrm{keV}$ at $25 \mathrm{~cm}[8,11]$. The point sources were measured for 3600 seconds. 


\section{Military Technical College \\ Kobry El-Kobbah, Cairo, Egypt}

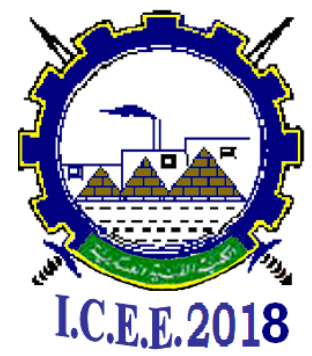

$9^{\text {th }}$ International Conference on

Chemical \& Environmental

Engineering

3-5 April 2018

\section{$2.72 \pi$ and $4 \pi$ geometry measurement:}

Two experimental efficiency curves were established using p-type detector $100 \%$ of two standard sources with the same density $(1.5 \mathrm{~g} / \mathrm{cm} 3)$ at different positions from the crystal (2ח and $4 \Pi$ ) for 3600 seconds.

\subsection{Absolute efficiency parameter:}

Many terms must be considered to correct for and calculate the efficiency [12-14] as shown in the following equation (Eq.5). Using standard source of almost the same structure and geometry as the samples allows the elimination of the effect of variation of the geometry, solid angle and sample compositions [1].

$$
\varepsilon_{a b s}=\frac{C_{n e t}}{A_{c} I_{Y}\left(E_{Y}\right) m T k_{1} k_{2} k_{3} k_{4} k_{5}}
$$

$\varepsilon_{\text {abs }}$ is the efficiency at photo peak energy $\mathrm{E}, \mathrm{C}_{\mathrm{net}}$ is the corrected net peak area of the corresponding photo peak, $\mathrm{m}$ is the mass in $\mathrm{kg}$ of the measured sample. The $\mathrm{A}_{\mathrm{c}}$ is the activity concentrations, in $\mathrm{Bq} / \mathrm{kg}$, $\mathrm{I} \gamma(\mathrm{E} \gamma)$ is the emission probability of the gamma line corresponding to the peak energy, $\mathrm{k}_{1}$ is the correction factor for the nuclide decay from the time the sample was corrected for, the $\mathrm{k}_{2}$ is the correction factor for the nuclide decay during counting period measurement. The $\mathrm{k}_{3}$ is the correction factor for a self-attenuation in the measured sample compared with the calibration sample. The $\mathrm{k}_{4}$ is the correction factor for pulses loss due to random summing that if more than one photon is absorbed by the detector during a pulse sampling cycle, the sum of the energies of two (or more) is recorded in the spectrum instead of two (or more) different signals. Any full-energy photon that is summed with another pulse is not recorded in the single photon peak and represents a loss of counts or efficiency. This loss is count rate dependent. The $\mathrm{K}_{5}$ is the coincidence factor for those nuclides decaying through a cascade of successive photon emissions it depends on the nuclide decay scheme, on sample geometry and composition and on detector parameters [12-14].

\section{Results and Discussion:}

\subsection{Results of Voltage variation:}

When the bias voltage increase the charge collection improves [15]. Hence, the large numbers of pulses are recorded. Therefore, the efficiency curve is enhanced as illustrated in figure $(1, a-b)$, which represents effect of variation of the bias voltage on efficiency 


\section{Military Technical College \\ Kobry El-Kobbah, Cairo, Egypt}

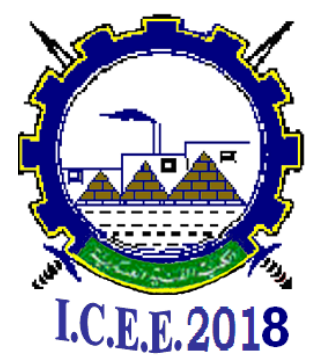

$9^{\text {th }}$ International Conference on

Chemical \& Environmental Engineering

3-5 April 2018

curve of HpGe. It is observed that in (p-type) detector, the difference in efficiency curves increases in lower energy below $300 \mathrm{keV}$ and decreases at higher energy above $300 \mathrm{keV}$ as going down in energy at different volts. While for (n-type), it is observed the reverse bias voltage enhances the depletion region that at low energy the efficiency curves at different voltages are almost the same and little difference at high energy.

The fully depleted region was achieved at $3300 \mathrm{~V}$ for (p-type) and 4000V for (n-type) respectively. The depletion voltage Vdep was found at $2300 \mathrm{~V}$ for (p-type) as shown in figure (2-a, b) [8]. Four different energies are plotted; $122 \mathrm{keV}, 356 \mathrm{keV}, 661 \mathrm{keV}$ and $1332 \mathrm{keV}$ to show the variation of voltage with absolute efficiency of the detector. It is observed that with raising the optimum voltage Vopt, the counts increase so that the photo-peak efficiency is increased at the four energies.

It is observed that, when the voltage is less than the depletion voltage, energy shifts occurred; figure (3) shows the comparison between energy shifts between optimum voltage $3300 \mathrm{~V}$ and $2000 \mathrm{~V}$. The error increased due to very poor charge collection, broadening and anomalous peak widths are obtained as shown in figure (4). Thus, the changing nature of the charge collection as a function of voltage variation leads to a great impact on the uncertainty.

The FWHM of the peak improves, as the voltage is raised. It stands to be about $1.7 \mathrm{keV}$ for $1332 \mathrm{keV}$ at $3300 \mathrm{~V}$ for p-type detector While, it was $2.8 \mathrm{keV}$ at $1300 \mathrm{keV}$ for n-type It was found to be $2.2 \mathrm{keV}$ at $4000 \mathrm{~V}$ while $4.2 \mathrm{keV}$ at $500 \mathrm{~V}$ (fig 5 -a, b)

\subsection{Results of source to detector distance:}

The maximum count value was observed at the surface of detector and decreases gradually as the source to detector distance increases as shown in figure (6-a,b).The lowenergy photons will be fully absorbed in the parts of the detector closest to the detector cap. The latter restriction is a consequence of lost counts due to true coincidence summing. It is a potential source of error whenever nuclides with a decay scheme with cascades of gamma rays are measured [4].True coincidence summing is geometry dependent and errors are particularly severe when sources are positioned very close to the detector [4]. For this reason, point sources with multi-gamma ray should not be used for close geometry to detector; for efficiency calibrations. The relative effect of summing can be reduced by reducing the solid angle or source to detector distance [13]. There is a limit as to how far away one can practically place a source of low activity So when the point sources are used to make efficiency calibration, it is recommended to be carried out at optimum source to detector distance of $25 \mathrm{~cm}$ to decrease the solid angle and the detector dead time although the count rate could be lowered by increasing the source-detector distance. 

Military Technical College
Kobry El-Kobbah, Cairo, Egypt

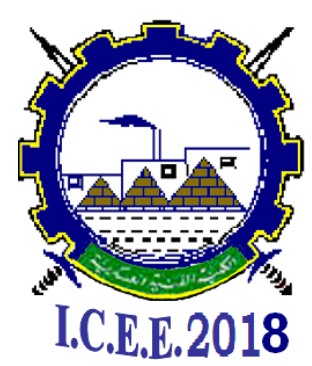

$9^{\text {th }}$ International Conference on

Chemical \& Environmental Engineering

3-5 April 2018

The point source efficiency at the detector cap is shown in Figure $(7-a, b)$. In these measurements, the detector diameter is less important to the efficiency than the dead layer and end cap attenuation. The (p-type) has the lowest efficiency at low energies, while for (n-type), it has the highest efficiency [16].

It is observed that at the detector cap, the dead time was found 30\% for p-type and $94 \%$ for n-type detector. It decreased as the distance from the detector increases to be $0.85 \%$, $7 \%$ at $25 \mathrm{~cm}$ respectively. The relation between the source to detector distance and dead time percentage is shown in fig. (8).

The best FWHM can be obtained by increasing the distance from the detector as shown in Figure (9-a, b). At the detector cap, the FWHM for $1332 \mathrm{keV}$ is $2.1 \mathrm{keV}$ and $2.9 \mathrm{keV}$ for p-type and n-type respectively. On the other hand it becomes 1.75 and $1.98 \mathrm{keV}$ at $25 \mathrm{~cm}$.

\subsection{Difference between point and bulk source Results:}

Efficiency curves of point and bulk sources are plotted in Figure (10-a, b) using p-type detector of $100 \%$. The results obtained are logic as that the efficiency curve of point source are much greater than the bulk source with different geometry. Because of the point sources are available as small deposits on thin backing material, so that they are non-absorbing sources with negligible volume, mass and density with the highest solid angle as mentioned in Equation (5). Unlike the bulk sources where the gamma rays can be attenuated by self-absorption within the sample material itself (equation 4). The calculation of an effective solid angle is complicated because every point within the bulk source has a different aspect on the detector and therefore will contribute to the overall gamma-ray intensity to a different degree [4]

\subsection{Results of comparison between detector types:}

The photo-peak detection efficiency as a function of energy shows that there will always a great deal of variation depending on detector type, size and configuration [2] as shown in figure (11). At low energy, it is observed that, below $122 \mathrm{KeV}$ (knee curve), the n-type detector has better efficiency than p-type detector, starting from 300keV [11]. The difference increases as going down in energy. This is because of the dead layer of the (ptype) that is much larger than of the (n-type). Any gamma rays stopped in the dead layer do not produce an output. This does not mean that the (p-type) cannot measure low energy photo peak, it simply means that it is not as sensitive as the (n-type) while the FWHM for p-type is better than n-type. 

Military Technical College
Kobry El-Kobbah, Cairo, Egypt

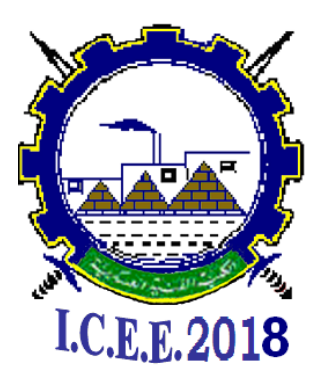

$9^{\text {th }}$ International Conference on

Chemical \& Environmental

Engineering

3-5 April 2018

\subsection{Results of density effect:}

Fig.(12) shows the effect of two standard sources with different densities and constant volume on detection efficiency. The use of efficiency curve established using a standard source matrix different from that of the investigated samples leads to above and/or down the estimated value of the measured activity. Figure (13) shows simulated efficiency curves carried out by using point sources as reference efficiency curves for Angel-3 software [7] to generate different efficiency calibration curves with different density or geometry samples which is needed especially for dense samples as phosphate samples, Black sand and separated geological minerals. It is observed that as the density of source increases from 1 to $2.5 \mathrm{~g} / \mathrm{cm} 3$ the efficiency of the used detector decreases from 0.045 to 0.027 at $122 \mathrm{keV}$ for low energy and as going down of the curve at higher energy the effect of the density decreased. For higher-energy gamma rays (> $250 \mathrm{keV})$ the uncertainties associated with mass attenuation coefficient are small, typically less than $10 \%$ [17]. For low energy gamma rays the mass-attenuation coefficient becomes very large to the elemental composition of the source matrix it has to make corrections in order to consider the differences in densities and compositions between the real and calibration conditions [18].

\subsection{Comparison between $2 \pi$ and $4 \pi$ geometry measurement Results:}

It is observed that $4 \Pi$ geometry measurement has a higher efficiency than $2 \Pi$ because the true coincidence summing are higher when measurements are performed in (near $4 \pi$ geometry) as in well-type HpGe detector [8]. As it is mentioned above, this is because the sample-detector solid angle is much higher (near $4 \pi$ geometry of measurement) and increases the probability of coincidence summing occurrence. Where, the relative effect of summing can be reduced by reducing the solid angle. So, it is recommended for measuring low activity samples to use $4 \Pi$ geometry measurement; not for high activity sample. Changing counting geometry needs solid angle geometry and coincidence summing corrections [12] See fig.14.

\section{Summary and Conclusion:}

The validation and verification $(\mathrm{V} \& \mathrm{~V})$ of the parameters affecting the $\mathrm{HpGe}$ spectrometers performance have been carried out in this study. A series of measurements using certified point and bulk standard sources to check the declared values of the HpGe detector technical specifications were performed.

It was verified that the efficiency of the detectors is the maximum at the certified fully depleted voltage with the best FWHM. When the point sources are used to draw 

Military Technical College
Kobry El-Kobbah, Cairo, Egypt

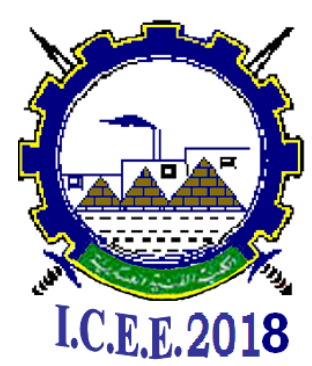

$9^{\text {th }}$ International Conference

Chemical \& Environmental

Engineering

3-5 April 2018

efficiency calibration curve, the source to detector distance at least $10 \mathrm{~cm}$ and preferably $25 \mathrm{~cm}$ is recommended to decrease the coincidence summing effect and the detector dead time percentage. The efficiency curves for any detection systems assuming any geometrical shape of the source container density can be simulated using Angle-3 software. The results show that the use of n-type $\mathrm{HpGe}$ detector is recommended rather than p-type. It has better efficiency and covers broad energies from $10 \mathrm{keV}$ to $3 \mathrm{MeV}$. However, p-type detector has better FWHM. As the density of source (sample) increases from 1 to $2.5 \mathrm{~g} / \mathrm{cm} 3$, the efficiency of the detectors decreases from 0.045 to 0.027 at $122 \mathrm{keV}$ low energy, while it went down the curve at higher energy; the effect of the density decreased .The efficiency of small geometry (sample) is better than the large one. As the surface surrounding the crystal (by the sample) increase, the higher the absolute efficiency and the lesser of the MDA as well. Generally, in order to obtain very accurate and real results, the samples must be counted under the same measuring conditions of standard (reference) and as those of the same system that has been calibrated.

\section{References}

[1] Abdel-Rahman, M.A. and S.A. El-Mongy, Analysis of radioactivity levels and hazard assessment of black sand samples from Rashid area, Egypt. Nuclear Engineering and Technology, 2017. 49(8): p. 1752-1757.

[2] Knoll, G.F., Radiation detection and measurement. 2010: John Wiley \& Sons.

[3] Diab, H., HPGe Detector Efficiency Curve Evaluation for Low-Level Measurements. Arab Journal of Nuclear Sciences and Applications, 2015. 48(4): p. 53-59.

[4] Gilmore, G., Practical gamma-ray spectroscopy. 2011: John Wiley \& Sons.

[5] Sutton, G., The analysis of environmental materials using gamma spectrometry. 1993: Great Britain. Directorate of Fisheries Research.

[6] Vargas, M.J., N.C. Díaz, and D.P. Sánchez, Efficiency transfer in the calibration of a coaxial p-type HpGe detector using the Monte Carlo method. Applied Radiation and Isotopes, 2003. 58(6): p. 707-712.

[7] Bell, S., S. Judge, and P. Regan, An investigation of HPGe gamma efficiency calibration software (ANGLE V. 3) for applications in nuclear decommissioning. Applied Radiation and Isotopes, 2012. 70(12): p. 2737-2741.

[8] Fairstein, E. and S. Wagner, IEEE Standard Test Procedures for Germanium GammaRay Detectors. IEEE Std, 1996: p. 325-1996.

[9] ANSI. American National Standard for Calibration and Use of Germanium Spectrometers for the Measurement of Gamma-Ray Emission Rates of Radionuclides. in Revision of ANSI, IEEE. 1999. The Institute of Electrical and Electronics Engineers, Inc. 
Military Technical College Kobry El-Kobbah, Cairo, Egypt

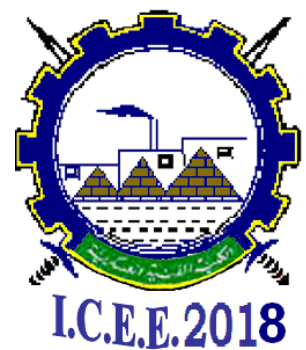

$9^{\text {th }}$ International Conference on

Chemical \& Environmental Engineering

3-5 April 2018

[10] Nelson, K.E., T.B. Gosnell, and D.A. Knapp, The effect of gamma-ray detector energy resolution on the ability to identify radioactive sources. 2009, Lawrence Livermore National Laboratory (LLNL), Livermore, CA.

[11] Twomey, T., The Best Choice of High Purity Germanium (HPGe) Detectors. ORTEC (USA), 2003.6.

[12] Cabal, F.P., et al., Monte Carlo based geometrical model for efficiency calculation of an n-type HPGe detector. Applied Radiation and Isotopes, 2010. 68(12): p. 24032408.

[13] Park, T. and W. Jeon, Measurement of radioactive samples in Marinelli beakers by gamma-ray spectrometry. Journal of Radioanalytical and Nuclear Chemistry, 1995. 193(1): p. 133-144.

[14] Abbas, M.I., Y.S. Selim, and M. Bassiouni, HPGe detector photopeak efficiency calculation including self-absorption and coincidence corrections for cylindrical sources using compact analytical expressions. Radiation Physics and Chemistry, 2001. 61(3): p. 429-431.

[15] Ali, F.A., Measurements of naturally occurring radioactive materials (NORMs) in environmental samples. 2008, University of Surrey.

[16] Keyser, R. and T. Twomey, Efficiency for close geometries and extended sources of a p-type germanium detector with low-energy sensitivity. Journal of radioanalytical and nuclear chemistry, 2007. 271(1): p. 55-61.

[17] ANSI. American National Standard for Calibration of Germanium Detectors for InSitu Gamma-Ray Measurements. 2002. The Institute of Electrical and Electronics Engineers, Inc.

[18] Pérez-Moreno, J., et al., A comprehensive calibration method of Ge detectors for low-level gamma-spectrometry measurements. Nuclear Instruments and Methods in Physics Research Section A: Accelerators, Spectrometers, Detectors and Associated Equipment, 2002. 491(1): p. 152-162. 
Military Technical College Kobry El-Kobbah, Cairo, Egypt

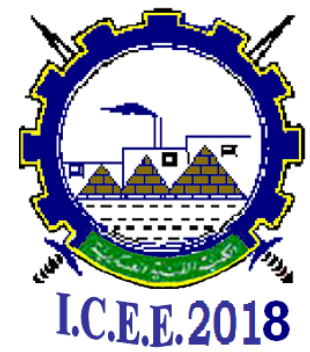

$9^{\text {th }}$ International Conference on

Chemical \& Environmental

Engineering

3-5 April 2018

Table1. Main technical specifications of the detectors

\begin{tabular}{cccccccc}
\hline Detector & $\begin{array}{c}\text { Detector } \\
\text { model }\end{array}$ & type & $\begin{array}{c}\text { Relative } \\
\text { Efficiency }\end{array}$ & $\begin{array}{c}\text { Crystal } \\
\text { length/diameter } \\
(\mathrm{mm})\end{array}$ & $\begin{array}{c}\text { Cooling } \\
\text { system }\end{array}$ & $\begin{array}{c}\text { Energy resolution } \\
122 \\
\mathrm{keV}\end{array}$ & $\begin{array}{c}\text { at } \\
1332.5 \\
\mathrm{keV}\end{array}$ \\
\hline A & Co axial & P-Type & $50 \%$ & $63.4 / 65.7$ & Cryo-cycle & 1.0 & 1.9 \\
B & GMX & N-Type & $50 \%$ & $67.5 / 63$ & x-cooler-II & 0.96 & 2.2 \\
C & GEM & P-Type & $100 \%$ & $93.4 / 79.4$ & x-cooler-II & 1.32 & 2.1 \\
\hline
\end{tabular}

Table 2.The certified activities of the radionuclides of the point sources

\begin{tabular}{|c|c|c|}
\hline Nuclide & Activity (Bq) & Uncertainty (\%) \\
\hline Cs-137 & 34408 & $\pm 20 \%$ \\
\hline Co-60 & 24455 & $\pm 20 \%$ \\
\hline Co-57 & 1970 & $\pm 20 \%$ \\
\hline Ba-133 & 30230 & $\pm 20 \%$ \\
\hline
\end{tabular}

Table 3: The certified activities of the radionuclides for bulk source

\begin{tabular}{|c|c|c|c|}
\hline Nuclide & Energy $(\mathrm{KeV})$ & Half-life, Days & Gamma/S \\
\hline Am-241 & 59.5 & $1.580 \mathrm{E}+08$ & $2.054 \mathrm{E}+03$ \\
\hline Cd-109 & 88.0 & $4.626 \mathrm{E}+02$ & $2.835 \mathrm{E}+03$ \\
\hline Co-57 & 122.1 & $2.718 \mathrm{E}+02$ & $1.529 \mathrm{E}+03$ \\
\hline Ce-139 & 165.9 & $1.376 \mathrm{E}+02$ & $2.131 \mathrm{E}+03$ \\
\hline Hg-203 & 279.2 & $4.661 \mathrm{E}+01$ & $4.954 \mathrm{E}+03$ \\
\hline Sn-113 & 391.7 & $1.151 \mathrm{E}+02$ & $2.972 \mathrm{E}+03$ \\
\hline Cs-137 & 661.7 & $1.098 \mathrm{E}+04$ & $1.892 \mathrm{E}+03$ \\
\hline Y-88 & 898.0 & $1.066 \mathrm{E}+02$ & $7.256 \mathrm{E}+03$ \\
\hline Co-60 & 1173.2 & $1.925 \mathrm{E}+03$ & $3.619 \mathrm{E}+03$ \\
\hline Co-60 & 1332.5 & $1.925 \mathrm{E}+03$ & $3.619 \mathrm{E}+03$ \\
\hline Y-88 & 1836.1 & $1.066 \mathrm{E}+02$ & $7.681 \mathrm{E}+03$ \\
\hline
\end{tabular}



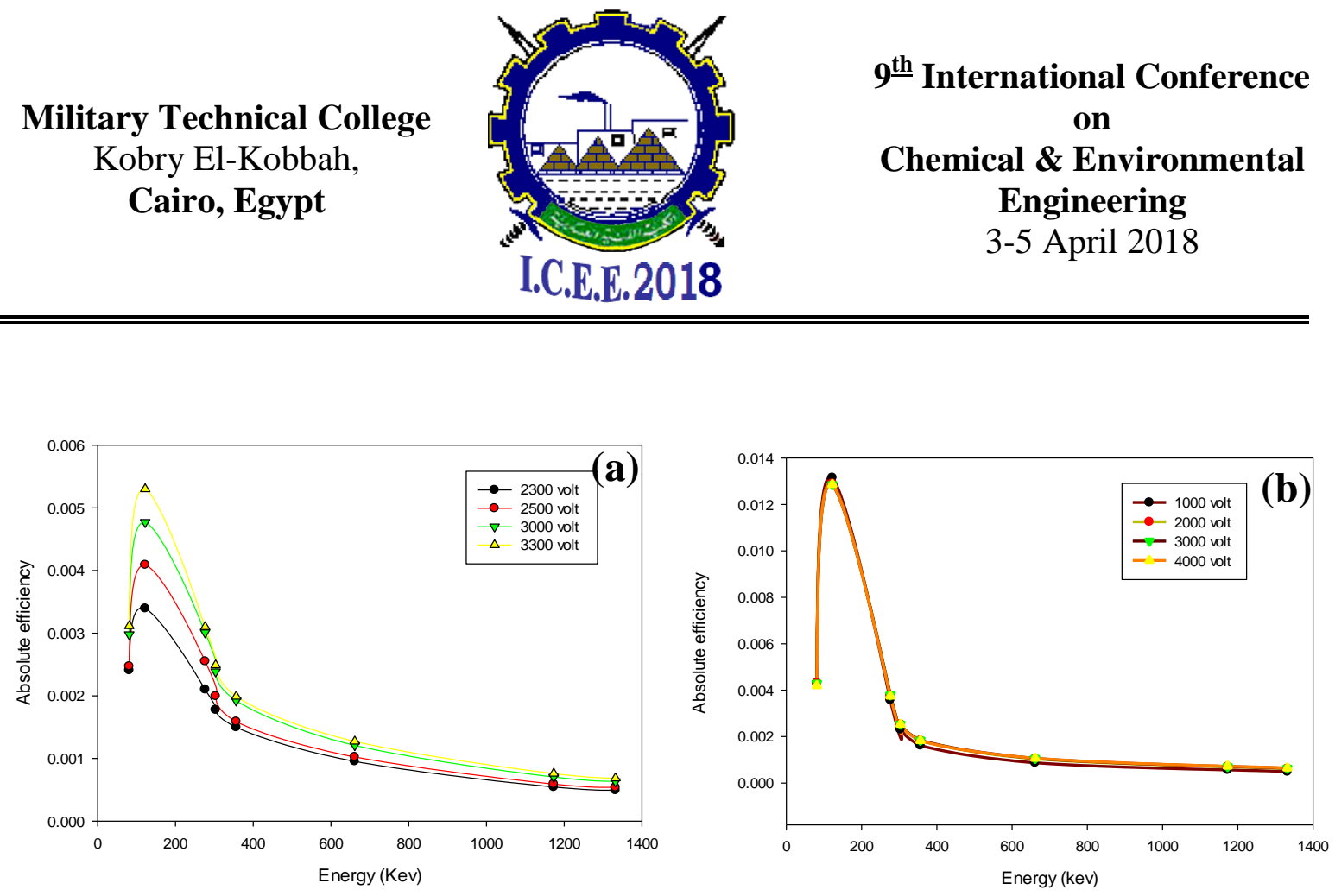

Fig.1. Efficiency curves at different voltages of two HpGe (a) p-type and (b) n-type
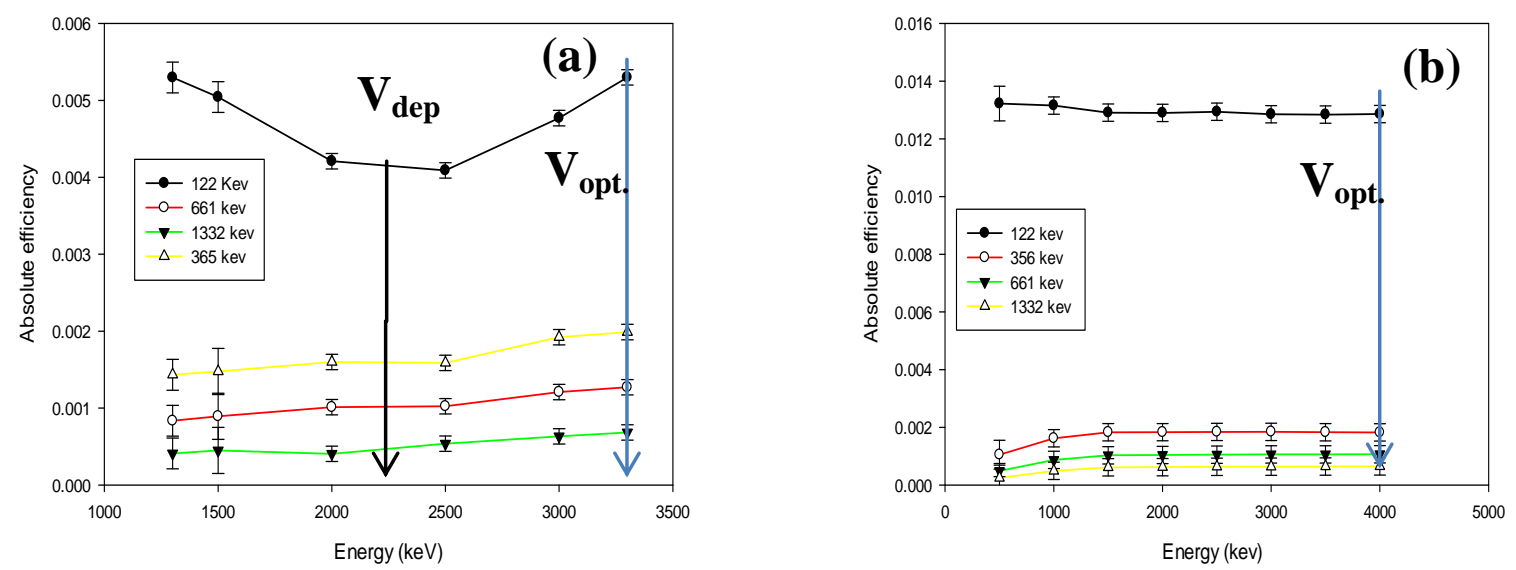

Fig.2. Effect of variation of the bias voltage at different energies of $\mathrm{HpGe}$ (a) $\mathrm{p}$-type and (b) n-type 
Military Technical College

Kobry El-Kobbah,

Cairo, Egypt

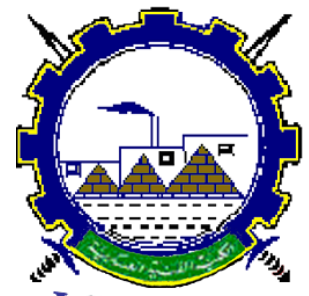

I.C.E.E.2018 $9^{\text {th }}$ International Conference on

Chemical \& Environmental

Engineering

3-5 April 2018

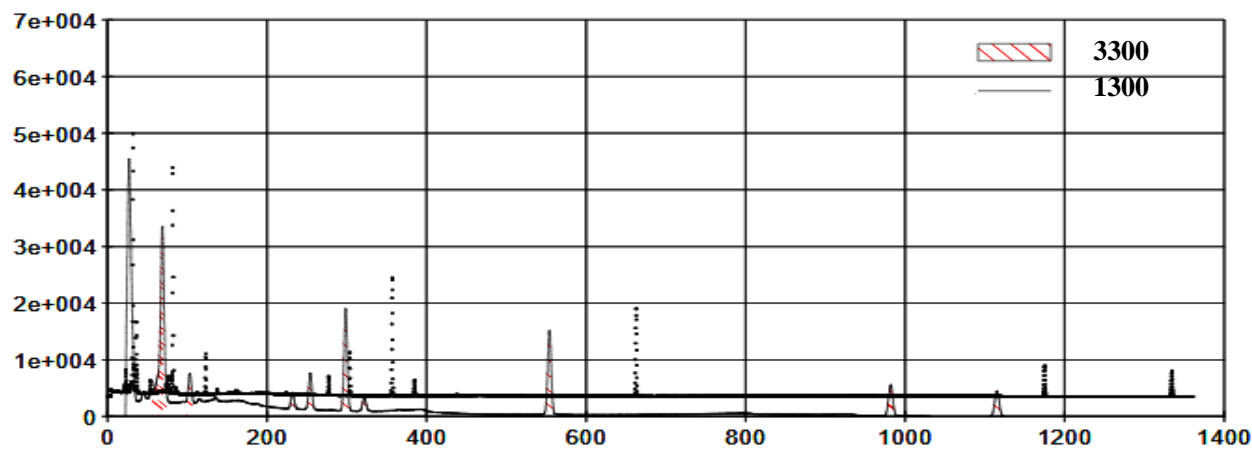

Fig.3. Peak energy shift before depletion voltage (1500V) and after depletion voltage (3300V)
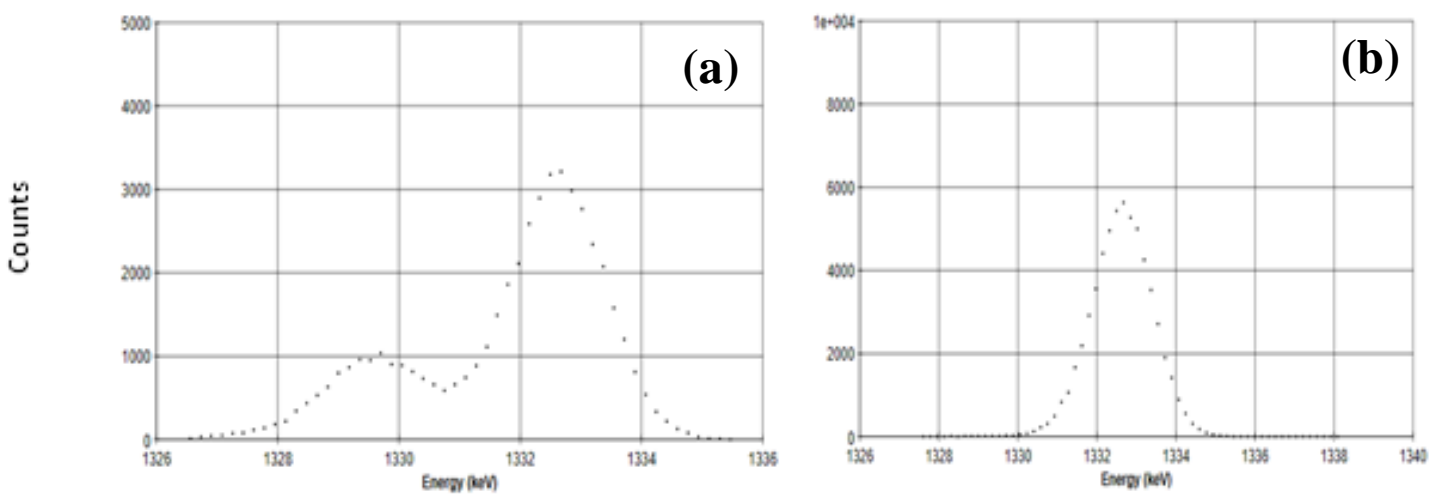

Fig.4. Anomalous and ideal peak widths at $1332 \mathrm{keV}$ (a)before and (b)after depletion voltage 

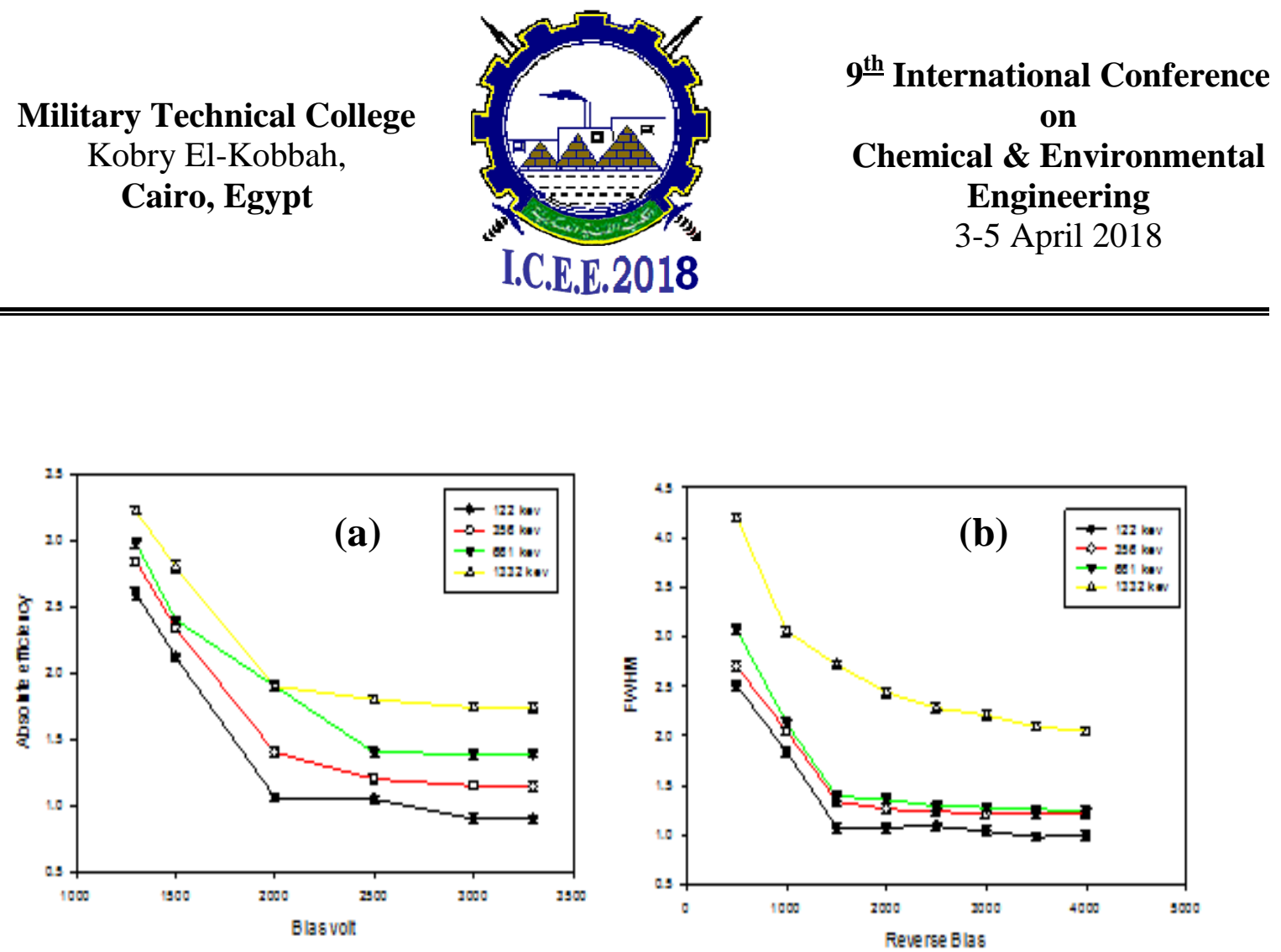

Fig.5. Effect of voltage variation on FWHM for (a) p-type (b) n-type
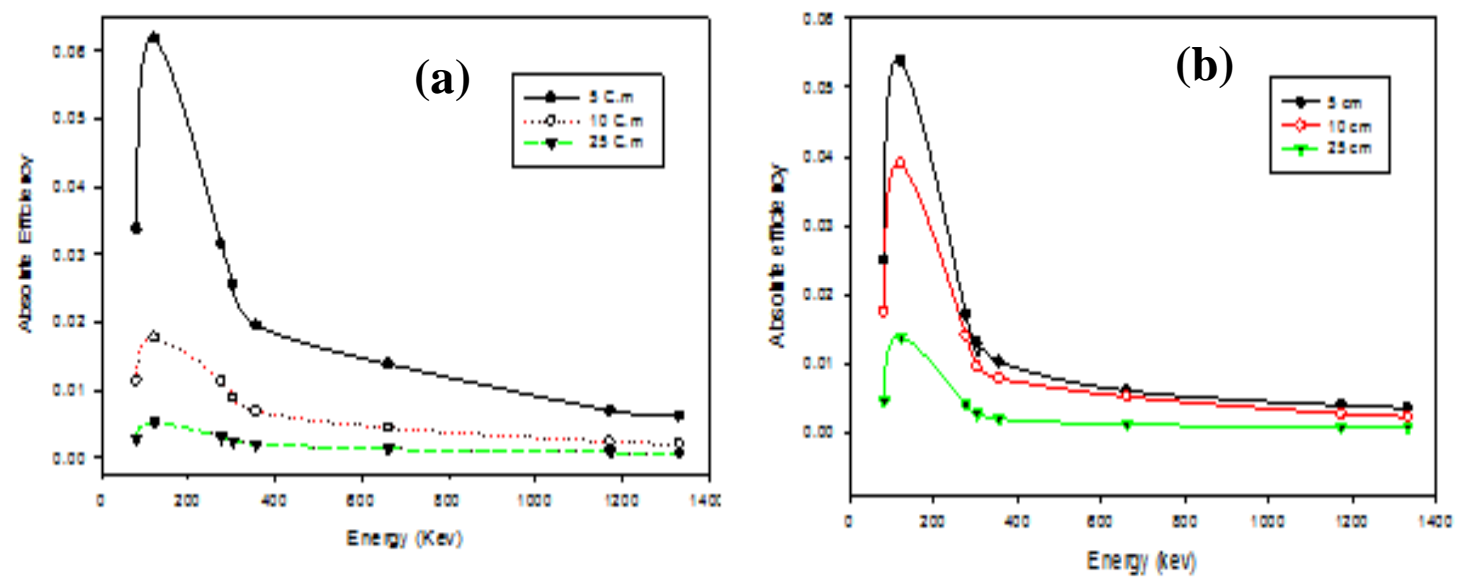

Fig.6. Variation of source to detector distance and efficiency for (a)p-type (b) n-type 


\begin{tabular}{|l|l|}
\hline Proceeding of the $9^{\text {th }}$ ICEE Conference 3-5 April 2018 & NRA
\end{tabular}
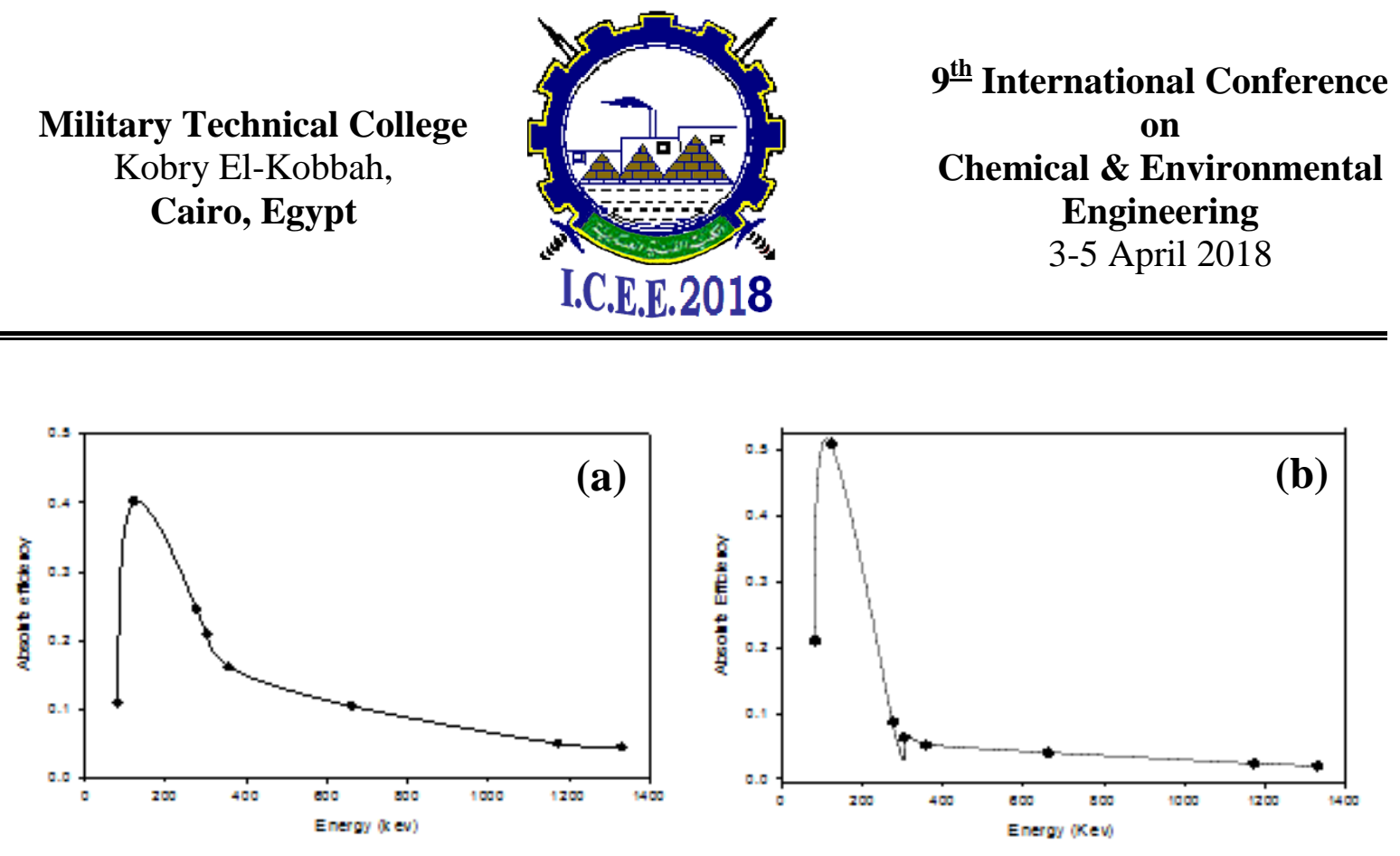

Fig.7. Absolute efficiency at detector cap for (a) p-type (b) n-type

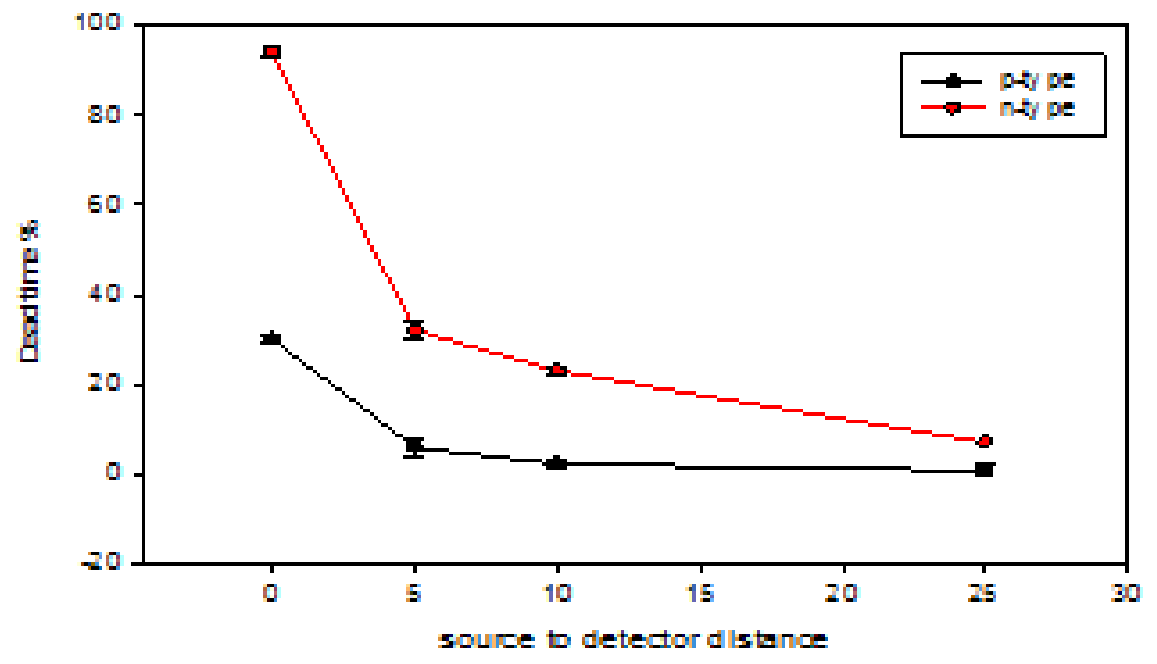

Fig.8. Relation between source to detector distance and dead time percentage for p-type and n-type 


$\begin{aligned} & \text { Military Technical College } \\ & \text { Kobry El-Kobbah, } \\ & \text { Cairo, Egypt }\end{aligned}$
C.C.E.E.2018
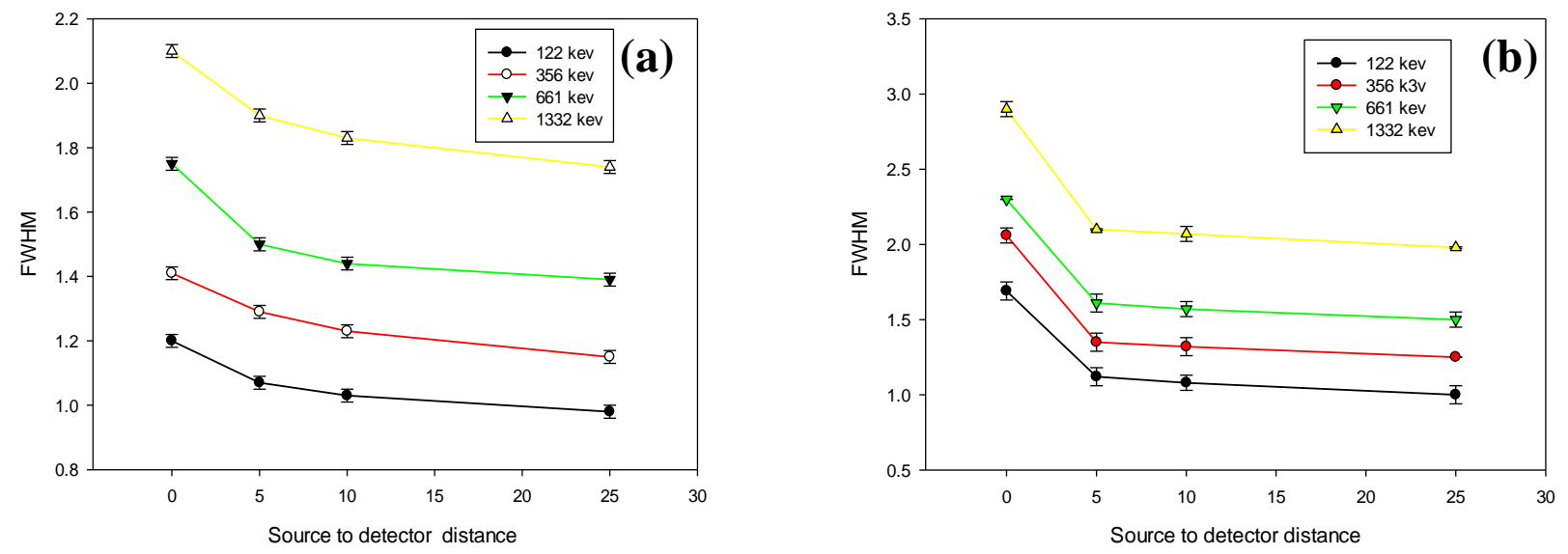

Fig.9. Relation between source to detector distance and FWHM for (a) p-type (b) n-type
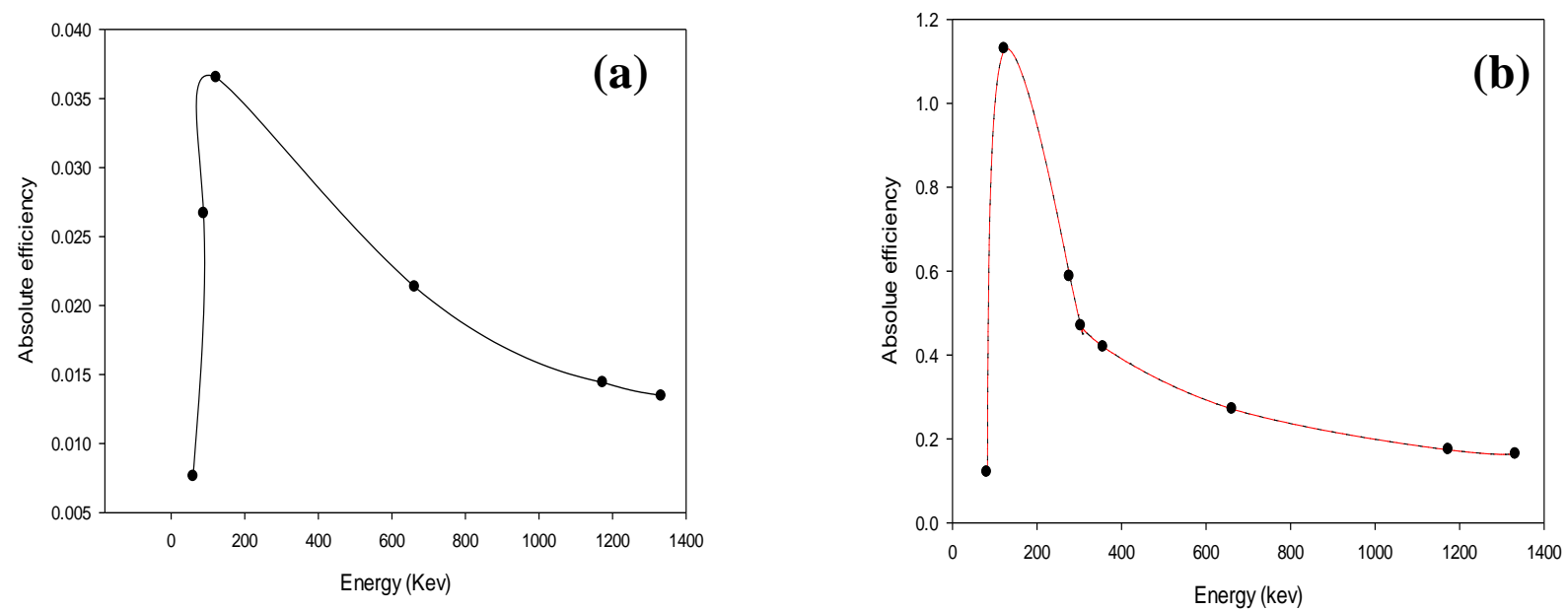

Fig.10. Difference of efficiency between (a) bulk source and (b)point source at detector cap 
Military Technical College

Kobry El-Kobbah,

Cairo, Egypt

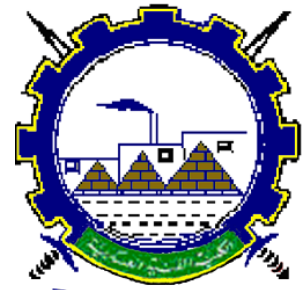

I.C.E.E.2018 $9^{\text {th }}$ International Conference on

Chemical \& Environmental

Engineering

3-5 April 2018

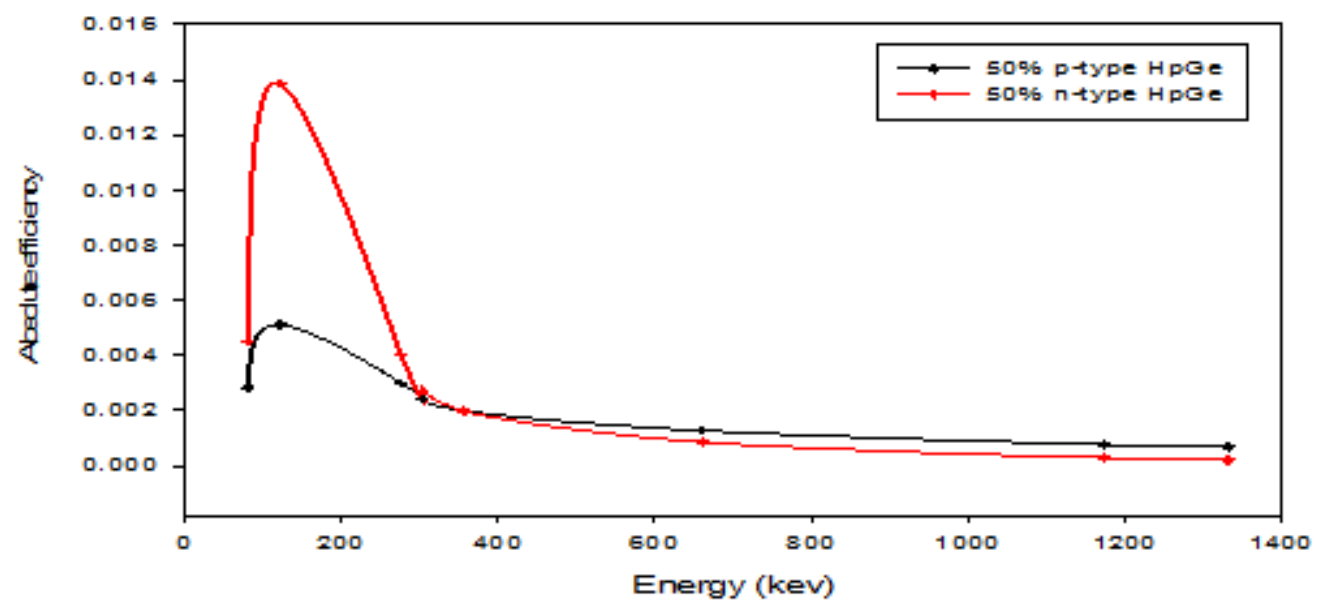

Fig 11. Absolute efficiency curves for $50 \%$ p-type and $50 \%$ n-type HpGe detectors using point sources at $25 \mathrm{~cm}$

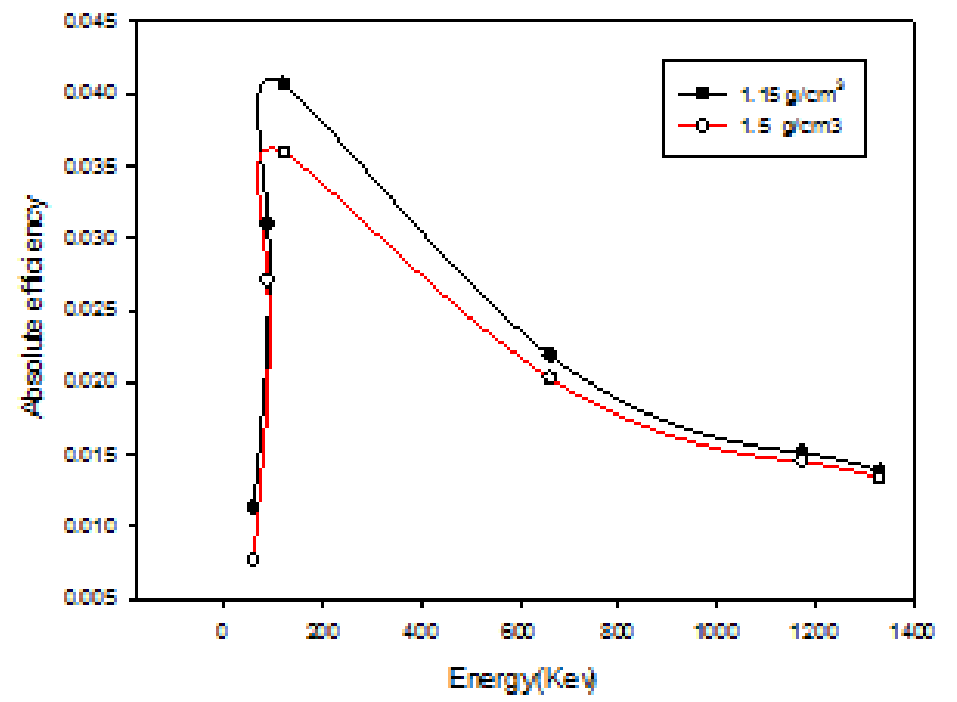

Fig 12. Effect of two bulk sources with different densities and constant volume on detection efficiency 
Military Technical College

Kobry El-Kobbah,

Cairo, Egypt

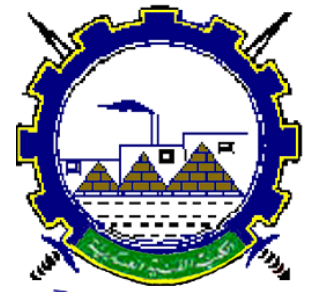

I.C.E.E.2018 $9^{\text {th }}$ International Conference on

Chemical \& Environmental

Engineering

3-5 April 2018

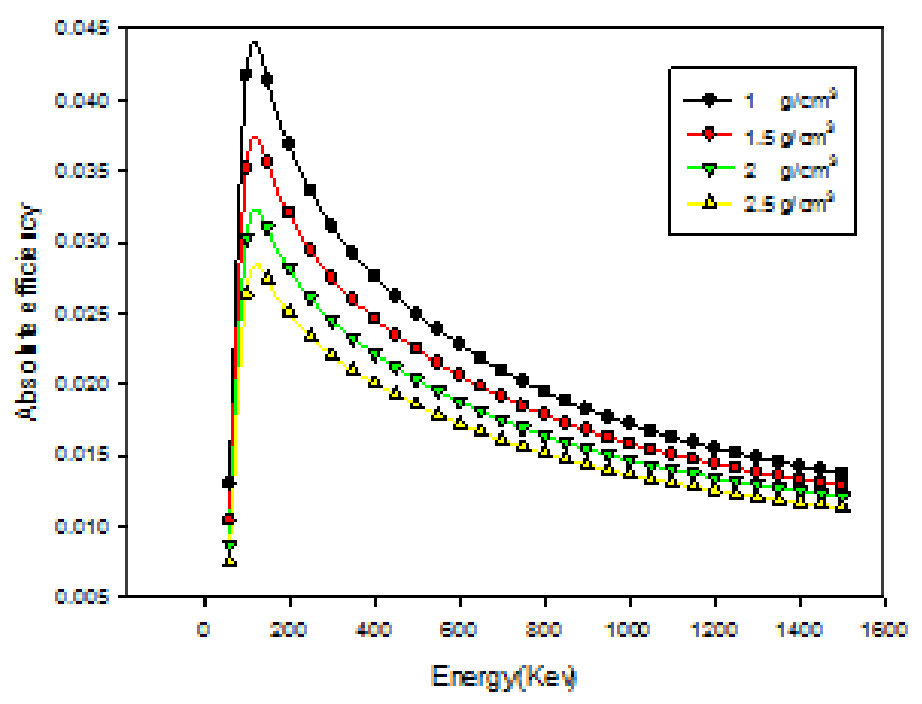

Fig.13 Calculated efficiency curves assuming different source matrix densities using (Angle-3 software)

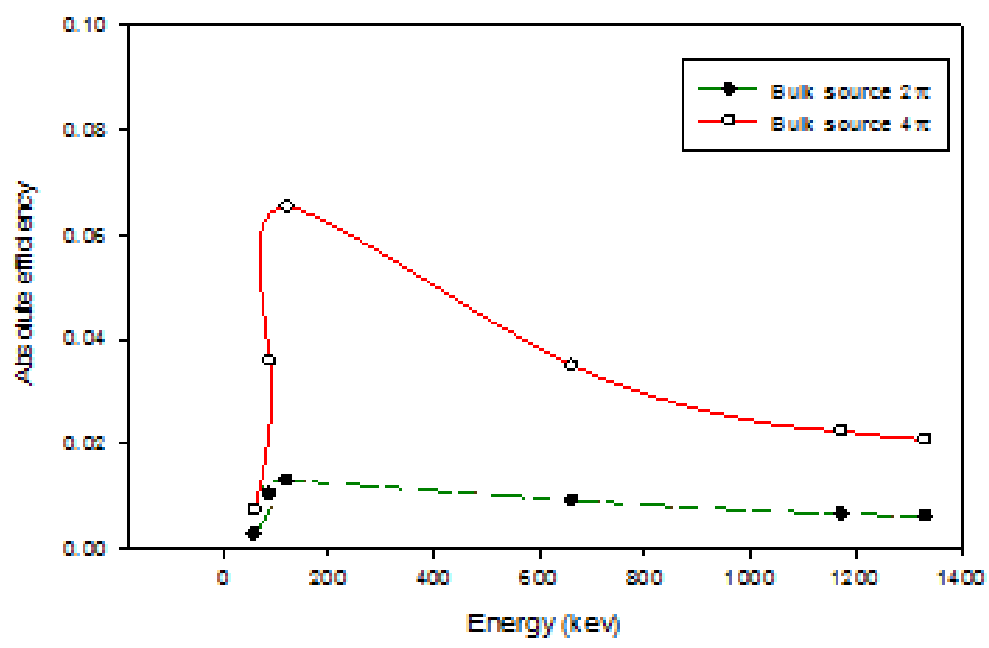

Fig.14 Absolute efficiency of two bulk sources at $2 \pi$ and $4 \pi$ geometry conditions 